Revista de Derecho YachaQ No 8 - Diciembre de 2017 Centro de Investigación de los Estudiantes de Derecho (CIED)

Universidad Nacional de San Antonio Abad del Cusco

ISSN: 2107-1197 (en línea)

ISSN: 1817-597X (impresa)

Fecha de recepción: 02/10/2017

Fecha de aceptación: 09/10/2017

[pp. 91-106]

\title{
La renuncia al cargo de congresista
}

\section{The resign from parliamentarian position}

\author{
Miguel Ángel Tinajeros Arteta ${ }^{1}$
}

\begin{abstract}
Resumen: La relación laboral a través de la cual los congresistas desempeñan sus funciones es, cuanto más, de naturaleza sui generis. No obstante, tal calidad no debe dar paso a la limitación de derechos, que por mandato constitucional, le asisten al congresista tan igual como a sus conciudadanos. En este sentido, cabe hacer análisis de si la limitación que se hace a los parlamentarios al imposibilitar la renuncia de su cargo persigue fines justificables, análisis que no puede ser realizado a cabalidad sino, desde los orígenes del carácter irrenunciable de la labor congresal. Siguiendo esta línea, su origen puede situarse de manera precisa en la Constitución de 1979, norma fundamental que revestía a esta limitación, el objetivo de evitar presiones de corte político que conllevaran a una renuncia forzada del congresista, aun en contra de su voluntad. Sin embargo, esta es una posibilidad que al día de hoy, debe ser superada; y buscar en cambio, que al igual que los titulares de los demás poderes públicos y organismos constitucionalmente autónomos, el congresista pueda ejercer sus facultades de renuncia.
\end{abstract}

Palabras clave: Irrenunciabilidad, derechos constitucionales, función pública, relación laboral, libertad, igualdad.

Abstract: The labour relationship through parliamentarians perform their functions has a sui generis nature. However, this nature can't allow a limitation of rights that parliamentarians owns because of a constitutional rule. In this line, it is necessary to analyze if this limitation blocks parliamentarians the possibility to resign to their positions pursue justifiable purposes; analysis that cannot be thoroughly done without considering the origins of the parliamentarian labour's unrenounciable quality. In this line, the origin can be precisely located on 1979 Constitution, essential norm that assigned to this limitation the objective to avoid politics pressures that end in a forced resign of parliamentarians, even though against their will. Nevertheless, this a possibility that have to get over, and instead, look for the parliamentary to exercise his faculty to resign, equally to the holders of the other public powers and constitutionally autonomous institutions.

Key words: Unrenounciable, constitutional rights, public function, working relationship, liberty, equality.

\footnotetext{
${ }^{1}$ Abogado graduado en la Universidad Nacional de San Antonio Abad del Cusco, becario de la Agencia Española de Cooperación Internacional, con Maestría en Derecho Civil y Procesal Civil en la Universidad Nacional de San Antonio Abad del Cusco. Estudios de Doctorado en Derecho en la Universidad del País Vasco. Ha ejercido cátedra universitaria en las asignaturas de Derecho Laboral y Derecho Constitucional, en la Universidad Nacional de San Antonio Abad del Cusco y Universidad Alas Peruanas. Jefe de la Unidad de Asesoría Jurídica de la Zona Registral No X Sede Cusco. migueltinajeros@hotmail.com YachaQ8
} 


\title{
La Renuncia Al cargo De Congresista
}

\author{
Miguel Ángel Tinajeros \\ Arteta. \\ Abogado graduado en la \\ Universidad Nacional de \\ San Antonio Abad del Cusco, \\ becario de la Agencia Española \\ de Cooperación Internacional, \\ con Maestría en Derecho \\ Civil y Procesal Civil en la \\ Universidad Nacional de \\ San Antonio Abad del Cusco, \\ estudios de Doctorado en \\ Derecho en la Universidad \\ del País Vasco. Ha ejercido \\ catedra universitaria en las \\ asignaturas de Derecho Laboral \\ y Derecho Constitucional, en \\ la Universidad Nacional de \\ San Antonio Abad del Cusco \\ y Universidad Alas Peruanas. \\ Jefe de la Unidad de Asesoría \\ Jurídica de la Zona Registral $N^{o}$ \\ $X$ Sede Cusco.
}

SUMARIO. 1.-Introducción. 2.-Antecedentes constitucionales. 3.-El texto constitucional actual. 4.- Fundamentos de la irrenunciabilidad. 5.- Fundamentos de la renunciabilidad. 6.- La relación laboral del congresista. 7.- Límites a la renuncia al cargo de congresista. 8.Conclusiones.

\section{1.- Introducción}

$\mathrm{E}_{1}$ presente trabajo tiene por finalidad, realizar un estudio respecto de la posibilidad de presentación de la renuncia al cargo de congresista, como una forma de extinción de la relación laboral existente entre el parlamentario y el Estado.

El cargo de congresista tiene la calidad de irrenunciable de conformidad con el artículo 95 de la Constitución Política del Perú, en concordancia con el artículo 15 del Reglamento del Congreso de la República del Perú; sin embargo, el presente estudio trata de analizar este tema, principalmente desde el ámbito del Derecho Laboral, también se analizará algunos derechos constitucionales que son lesionados, como consecuencia de considerar el cargo de congresista como irrenunciable. 
No podemos dejar de mencionar, que la iniciativa de realizar este trabajo, tiene como fuente, como fundamento e inspiración, la renuncia presentada al cargo de congresista por parte del ex parlamentario Javier Valle Riestra.

\section{2.- Antecedentes Constitucionales}

A efectos de entender el debate sobre la posibilidad de la renuncia al cargo de congresista, debemos recurrir a los antecedentes legislativos, motivo por el cual necesariamente debemos tener en cuenta la constitución histórica, entendida esta como "el espacio valorativo extra-normativo, formado por un conjunto de instituciones y principios que integran una tradición democrática y republicana, construida por varias generaciones de peruanos, que es necesario rescatar y revalorar como proyecto histórico de Constitución. Esto es, trasciende lo meramente formal o la norma positiva"1

Al respecto tenemos que los textos constitucionales anteriores a la Constitución Política del Perú de 1993, sobre el mandato parlamentario decían lo siguiente:

\section{Constitución Política del Perú de 1828}

Artículo 46.- Todo Senador y Diputado puede ser reelegido, y sólo en este caso es renunciable al cargo.

\section{Constitución Política del Perú de 1834}

Artículo 49. Los senadores y diputados pueden ser reelegidos; y solo en este caso es renunciable el cargo.

\section{Constitución Política del Perú de 1839}

Artículo 24. Los Diputados y Senadores pueden ser reelegidos, y solo en este caso es renunciable el cargo.

\section{Constitución Política del Perú de 1856}

Artículo 53. El Congreso se renovará anualmente por terceras partes. Los representantes podrán ser reelectos y solo en este caso será renunciable el cargo.

\section{Constitución Política del Perú de 1860}

Artículo 58. Los Diputados y Senadores podrán ser reelectos, y sólo en este caso será renunciable el cargo.

\section{Constitución Política del Perú de 1867.}

Artículo 58. Los Representantes podrán ser reelectos; y solo en este caso será renunciable el cargo.

\footnotetext{
1 DOMINGUEZ HARO. Heder. La llamada Constitución Histórica. Diario El Peruano. 12 de agosto del 2011. Pag. 13.
} 


\section{Constitución Política del Perú de 1920.}

Artículo 82.- Los Diputados o Senadores podrán ser reelectos y sólo en este caso será renunciable el cargo.

\section{Constitución Política del Perú de 1933.}

Artículo 96.- El mandato legislativo es irrenunciable, salvo el caso de reelección. La renuncia se presentará a la respectiva Cámara.

\section{Constitución Política del Perú de 1979.}

Artículo 178.- El mandato legislativo es irrenunciable. Las sanciones disciplinarias que imponen las Cámaras a sus miembros y que implican supresión de funciones no pueden exceder de ciento veinte días de legislatura.

\section{3.- EI Texto Constitucional Actual}

La Constitución Política del Perú de 1993, sobre el mandato parlamentario prescribe lo siguiente:

Irrenunciabilidad del Mandato Legislativo.

Artículo 95.- El mandato legislativo es irrenunciable.

Las sanciones disciplinarias que impone el Congreso a los representantes y que implican suspensión de funciones no pueden exceder de ciento veinte días de legislatura.

\section{4.- Fundamentos de la Irrenunciabilidad}

\section{1.- El Antecedente Inmediato}

El antecedente inmediato del artículo 95 de la Constitución vigente, lo encontramos en el artículo 178 de la Constitución de 1979, por lo que previamente debemos remontarnos a dicho cuerpo normativo, que fue la primera que estableció el carácter absoluto de la irrenunciabilidad del cargo de congresista.

En palabras de Jorge Luis León Vásquez "Es necesario remitimos a la Constitución Política de 1979, a fin de conocer las razones que llevaron al constituyente a consagrar la prohibición de renuncia al mandato legislativo. Del debate constituyente de 1979 se puede apreciar que lo que se pretendió con la proscripción de la renuncia de los congresistas no fue sino proteger al parlamentario de las presiones provenientes de cualquier sector. Por ello, se señaló en principio que "si ponemos el concepto 'renunciable', exponemos a presiones al diputado y al senador"; en otros contextos se señaló que permitir la renuncia podría llevar a situaciones políticas extremas, como por ejemplo, la dimisión masiva de representantes. De ahí que se aprobara, con algunos atisbos de contradicción, la supresión de lo que la Constitución de 1933 sí permitía”².

\footnotetext{
2 LEÓN VÁSQUEZ, Jorge Luis. La Constitución Comentada. Gaceta Jurídica. Lima 2005. Tomo II. Pag. 106.
} 


\section{2.- La no sujeción al mandato imperativo}

Conforme se tiene de la prescripción del artículo 93 de la Constitución de 1993, Los congresistas representan a la Nación. No están sujetos a mandato imperativo ni a interpelación.

La no sujeción al mandato imperativo, tiene que ver con el mandato representativo, pues los congresistas se desvinculan de sus electores una vez que asumen funciones, puesto que si bien, deben su elección a sus electores, no los representa, sino más bien representan a la nación.

Por no sujeción al mandato imperativo, se debe entender, la independencia en el ejercicio de sus funciones, sin presiones o consignas por parte del congreso, o de los otros poderes públicos, de sectores de la población, de la bancada, del propio partido por el cual fue elegido, por tanto, no tiene restricciones, ni intervenciones de terceros.

\section{3.- Prerrogativas Parlamentarias}

Las prerrogativas de los parlamentarios no son privilegios personales, sino garantías funcionales, que protegen no al parlamentario en cuanto tal, sino a la función parlamentaria que él desempeña. Son por tanto, reglas objetivas que tienen que ser aplicadas siempre, independientemente de cuál sea la voluntad personal del parlamentario afectado, son pues prerrogativas irrenunciables, sobre las que no puede disponer nadie (inviolabilidad) o solo la cámara (inmunidad), pero nunca el parlamentario. ${ }^{45}$

La inviolabilidad es la más importante. La finalidad de esta prerrogativa es clara, se trata sencillamente, de proteger la libertad del parlamentario en el ejercicio de sus funciones, en cuanto tal. Ni las opiniones expresadas en el ejercicio de las mismas, ni los votos emitidos en las decisiones parlamentarias deben suponer para él, consecuencias negativas o sanción jurídica del tipo que sea ${ }^{46}$.

La inviolabilidad por tanto, se refiere a la protección de los congresistas respecto de sus opiniones y los votos que emiten en el ejercicio de sus funciones. Es una garantía sustantiva.

En palabras de Elipe León Martinez, "La inviolabilidad implica una absoluta irresponsabilidad de los parlamentarios, no solo, por las manifestaciones y opiniones expresadas en el ejercicio de sus cargos, sino también por los votos emitidos...la garantía de la inviolabilidad se encuentra en su caracterización de irrenunciable, absoluta y permanente".

Mientras que la inmunidad es una prerrogativa del congresista que evita que se realice un proceso penal e inclusive la detención del congresista, sin que previamente exista la autorización correspondiente del Congreso. Es una garantía procesal.

45 PÉREZ ROYO, Javier. Curso de Derecho Constitucional. Marcial Pons Ediciones Jurídicas. Madrid 2005. Pag. 766.

46 PÉREZ ROYO, Javier. Curso de Derecho Constitucional. Marcial Pons Ediciones Jurídicas. Madrid 2005. Pag. 766. 
Sobre la inmunidad Elipe León Martinez, nos informa y nos dice: la inmunidad debe considerarse como una garantía de las Asambleas, a fin de que no se quede alterada su composición y funcionamiento, asegurando su autonomía e independencia, frente a cualquier otro poder. Finalidad que podría quedar frustrada mediante la persecución, detención o prisión de sus miembros.

De lo anterior podemos apreciar que la irrenunciabilidad del cargo de congresista, no forma parte de las denominadas prerrogativas parlamentarias.

Conforme a los párrafos precedentes, podemos afirmar, que el fundamento de la irrenunciabilidad del cargo de congresista, radica en el interés de protección al congresista de algunas presiones, que se pudieran presentar respecto a su actuar y por otro lado, evitar que sus decisiones se vean influenciadas por los intereses ajenos al propio congresista, con lo cual se limitaría el ejercicio libre de su cargo. Pues bien a continuación procederemos a analizar porque es viable la renuncia al cargo de congresista.

\section{5.- Fundamentos de la Renunciabilidad}

A fin de tener un panorama más amplio sobre la posibilidad de la renuncia al cargo de congresista, debemos tener en cuenta aspectos relacionados al tema constitucional, al político y al laboral.

\section{1.- Análisis Constitucional de la Renuncia al Cargo de Congresista}

Conforme al artículo 95 de la Constitución Política del Perú de 1993, el mandato parlamentario es irrenunciable, de primera intención entendemos que el congresista está impedido de renunciar a su cargo, sin embargo, veremos cómo es que esta norma lesiona y colisiona con otros derechos constitucionales.

D Uno de ellos es el derecho al libre desarrollo, regulado en el artículo 2, inciso 1 de la Constitución Política del Perú de 1993, "el libre desarrollo de la persona no es sino lo que en términos de antropología filosófica se llama su realización como ser humano".

En otros términos, proteger la libertad fenoménica significa la protección del "proyecto de vida" o libertad actuante, presente en el mundo. La importancia de la protección jurídica del "proyecto de vida" radica en que en él se juega nada menos que el destino de la persona, de cada persona. Es decir, lo que la persona decidió hacer en y con su vida ${ }^{6}$.

1. Pretender coactar esa libertad a un congresista que desea renunciar, por que ejercer ese cargo no lo satisface personal, profesional, social y porque no hasta económicamente, no es otra cosa que lesionar el derecho al libre desarrollo. Sobre el particular no podemos dejar de mencionar lo argumentado por el ex congresista Javier Valle Riestra, precisamente como consecuencia de su carta de renuncia al cargo de congresista: "Me tengo que marchar porque no he podido cumplir mi promesa de restaurar la

\footnotetext{
5 RUBIO CORREA, Marcial. Estudio de la Constitución Política de 1993. PUCP. Tomo I Lima 1999. Pag. 133.

6 FERNANDEZ SESAREGO, Carlos. La Constitución Comentada. Gaceta Jurídica. Lima 2005. Tomo II. Pag. 66.
} 
Constitución legítima de 1979, ni el bicameralismo. Este no es el viejo Parlamento que viví desde 1978. Tenemos un fetichismo asambleísta. Se tiene que estar enclaustrado en el hemiciclo. Se subestima el trabajo en las Comisiones o cualquier clase de actividad intelectual parlamentaria o de representación. Si uno no se la pasa bostezando horas de horas en el Pleno, escuchando debates bizantinos, es puesto en una lista negra en el diario oficial... No puedo soportar esta sevicia tres años y dos meses más"7.

Otro derecho que se lesiona con la irrenunciabilidad al cargo de congresista, es el derecho a la igualdad, prescrito en el artículo 2, inciso 2, de la Constitución de 1993. La igualdad ante la ley, “...es el supuesto de la igualdad como generalización, que expresa la superación del privilegio otorgado a un sector de ciudadanos y la construcción de normas jurídicas como dirigidas a un abstracto homo iuridicus, que es el hombre y el ciudadano..."

De tal forma, todas las personas que desarrollan una labor en el Estado, es decir, dentro del derecho público, o fuera de él, en el ámbito privado, tienen la facultad de renunciar al cargo que desempeñan, tienen el mismo derecho, porque es que este derecho se les extrae a los congresistas. Como veremos más adelante los otros funcionarios de los poderes del Estado, tienen el derecho a renunciar, inclusive el propio Presidente de la República como primer funcionario del país, no permitir la renuncia de los congresistas, es un trato discriminatorio.

$>$ Asimismo, se tiene que en el artículo 2, inciso 15, de la Constitución Política del Perú de 1993, se reconoce el derecho a la libertad de trabajo. Toda persona tiene derecho a: 15. A trabajar libremente, con sujeción a ley.

La libertad de trabajo consiste en el derecho de toda persona a decidir si trabaja o no, en que actividad y para quien, esta proclamada en nuestra Constitución (artículo 2,15 y 59) y por números instrumentos internacionales de derechos humanos, como la Declaración Universal de los Derechos Humanos (artículo 23.1) el Pacto Internacional de Derechos Económicos Sociales y Culturales (artículo 6.1) la Declaración Americana de los Derechos y Deberes del Hombre (Artículo XIV) y el Protocolo Adicional a la Convención Americana sobre Derechos Humanos en materia de Derechos Económicos Sociales y Culturales (artículo $6.1)^{9}$

No puede obligarse a una persona a trabajar, lo contrario significaría promover el trabajo forzoso. Lo cual es totalmente contradictorio con los principios y derechos fundamentales en el trabajo, cuya finalidad es la búsqueda del trabajo decente y que entre otros aspectos contiene la eliminación de toda forma de trabajo forzoso.

Sobre este tema "La OIT, plantea, en el marco de su Agenda Hemisférica para la promoción del trabajo decente, lineamientos de políticas orientados a fomentar la toma de conciencia de gobiernos y actores

\footnotetext{
49 VALLE RIESTRA, Javier. La viabilidad de la renuncia al cargo parlamentario. En Revista Institucional Nº 9 AMAG. Lima 2010. Pag. 39.

50 GREGORIO PECES - BARBA MARTINEZ. Curso de Derechos Fundamentales. Madrid 1996. Pag. 284.

51 NEVES MUJICA, Javier. Introducción al Derecho Laboral. Pontificia Universidad Católica del Perú. Fondo Editorial Lima 2003. Pag. 22.
} 
sociales; generar información para apoyar la formulación de políticas; adecuar la legislación para considerar el trabajo forzoso como delito grave e incrementar la efectividad de su sanción"10

$>\quad$ Otro derecho lesionado se encuentra en el artículo 23 de la Constitución Política del Perú de 1993 que regula El Estado y el Trabajo, y prescribe que: "Nadie está obligado a prestar trabajo sin retribución o sin su libre consentimiento”. Por tanto para realizar cualquier labor de carácter productivo, cualquier trabajo tiene que haber consentimiento de la persona, es decir, tiene que haber una voluntad de trabajo, lo contrario también significaría un trabajo forzoso, lo cual no está permitido por nuestra legislación constitucional, además de haber suscrito el Convenio 105 de la OIT, referido a la abolición del trabajo forzoso, sobre este particular, nos remitimos a los comentarios realizados respecto al artículo 2, inciso 15 de la Constitución y que obran líneas más arriba.

$>\quad$ Otro derecho constitucional lesionado con la irrenunciabilidad del cargo de congresista es el artículo 31 de la Constitución Política del Perú, que regula la Participación ciudadana en asuntos públicos, y prescribe que: Los ciudadanos tienen derecho a participar en los asuntos públicos mediante referéndum; iniciativa legislativa; remoción o revocación de autoridades y demanda de rendición de cuentas. Tienen también el derecho de ser elegidos y de elegir libremente a sus representantes, de acuerdo con las condiciones y procedimientos determinados por ley orgánica...

...Es nulo y punible todo acto que prohiba o limite al ciudadano el ejercicio de sus derechos.

Sobre el particular debemos tener presente lo que nos informa Jorge Luis León Vásquez: "El derecho de todas las personas a acceder a cargos públicos representativos ha sido consagrado por la Constitución de 1993 en su artículo 31. El contenido esencial del mismo estriba "en el acceso igualitario a las funciones y cargos públicos de carácter representativo, al mantenimiento en el mismo sin perturbaciones ilegítimas y a cesar libremente en el cargo mediante un acto de voluntad plenamente disponible para el representante público electo". En consecuencia, se puede afirmar que el derecho a renunciar a un cargo público representativo forma parte del derecho de acceder al mismo"11.

De lo cual podemos concluir que el derecho a acceder a un cargo público no termina con el simple acceso al cargo, sino también importa el desempeño en dicho cargo y por supuesto que el ciudadano pueda renunciar al mismo, en cuyo caso otro ciudadano, ejercerá su derecho a acceder al cargo público por ser accesitario.

$>$ Finalmente consideramos que la libertad de trabajo, también es un derecho lesionado con la irrenunciabilidad del cargo de congresista, pues bien, el artículo 59 de la Constitución Política del Perú de 1993, establece el Rol Económico del Estado, y prescribe que el Estado estimula la creación de riqueza y garantiza la libertad de trabajo...

\footnotetext{
10 LEVAGGI. Virgilio. Democracia y Trabajo Decente en América Latina. OIT. Lima 2006.

11 LEÓN VÁSQUEZ, Jorge Luis. La Constitución Comentada. Gaceta Jurídica. Lima 2005. Tomo II. Pag. 107.
} 
Sobre la libertad de trabajo el maestro Neves Mujica explica: "Si el trabajador no quiere cumplirla, el empleador puede sancionarlo, pero no puede compelerlo a trabajar. Lo mismo sucedería si se hubiera establecido un plazo de duración para la relación laboral y bastante antes de su vencimiento el trabajador decidiera ponerle fin. En este caso, podría haber lugar al pago de una indemnización por responsabilidad derivada del incumplimiento contractual, pero no imposición de trabajo. La libertad de trabajo opera, pues, desde el nacimiento de la relación laboral en adelante, a lo largo de toda su vida" ${ }^{\text {2 }}$. No permitir la renuncia al cargo de congresista es lesionar la libertad de trabajo.

\section{2.- Análisis Político de la Renuncia al Cargo de Congresista}

En cuanto respecta al aspecto político de la renuncia al cargo de congresista, consideramos que este hecho, no atenta de ninguna forma a la labor parlamentaria, pues esta tiene garantías como las que mencionamos anteriormente, como son la inviolabilidad y la inmunidad parlamentaria.

La posibilidad de la renuncia al cargo de congresista, no lesiona la independencia del ejercicio de la labor congresal, no influye en sus opiniones, ni tampoco respecto del voto que realice; de igual forma, esta posibilidad de renuncia del congresista, no debilita la función parlamentaria, se argumenta en contrario que el congresista podría ser inducido y hasta obligado a renunciar, quien sabe por quienes, sobre este extremo es imperioso citar a Javier Valle Riestra, el maestro nos dice: "Algunos timoratos vanidosos creen que pueden ser coaccionados para renunciar a su cargo parlamentario, pero, cuando se es un hombre enterizo y no un cobarde, nadie le saca a uno la renuncia contra su voluntad"13.

El jurista Francisco Eguiguren Praeli, sobre la irrenunciabilidad de los congresistas opina que: "Esta norma de irrenunciabilidad puede explicarse en los orígenes del parlamento, en la época de los albores de la lucha del parlamento frente al poder absoluto de los monarcas o de los gobernantes para evitar que mediante una presión los obligaran a renunciar, pero hoy en día en democracia eso está superado. Si el presidente puede renunciar que es la más alta autoridad política del país por qué no va a poder hacerlo un congresista, además no le genera ningún gasto al país, pues simplemente hay que aceptar la renuncia, declarar la vacancia y entra el accesitario en su lista" 14 , líneas más abajo, es aún más crítico cuando expresa: "Forma parte de este blindaje que se pusieron los congresistas: irrevocables, irrenunciables y no vacables, vamos intocables"15.

Conforme tenemos dicho líneas arriba, las prerrogativas parlamentarias, solo son la inviolabilidad y la inmunidad parlamentaria, por tanto, la renuncia al cargo de congresista no lesiona en modo alguno las prerrogativas parlamentarias.

Debemos reafirmarnos en el hecho que la posibilidad de la renuncia de los congresistas no limita en modo alguno las decisiones que tomen los parlamentarios, ni los pone en situación de riesgo, de desprotección o presión, ni tampoco, sus decisiones van estar sometidas a los designios de sus electores, de su partido o de grupos de poder.

\footnotetext{
12 NEVES MUJICA, Javier. Introducción al Derecho Laboral. Pontificia Universidad Católica del Perú. Fondo Editorial Lima 2003. Pag. 24.

13 VALLE RIESTRA, Javier. La viabilidad de la renuncia al cargo parlamentario. En Revista Institucional No 9 AMAG. Lima 2010. Pag. 42.

14 Revista Derecho y Sociedad No 31. Asociación Civil Derecho \& Sociedad. Entrevista realizada por Sandra Cecilia Chávez Torres y Ulises Medrana Recuay, al Doctor Francisco Eguiguren Praeli. El Parlamento Peruano y las Funciones del Parlamentario: lo que se Puede Mejorar. Año 2008. Pag. 19.

15 Idem
} 


\section{3.- Análisis Laboral de la Renuncia al Cargo de Congresista}

A continuación haremos un análisis desde el punto de vista del derecho laboral, respecto de la renuncia al cargo de congresista, estudiando algunos conceptos importantes.

\subsection{1.- La Renuncia}

Por renuncia "entendemos como la decisión libre del trabajador de separarse de su empleo en ejercicio de su derecho"16. Se trata de un acto unilateral del trabajador, y que inclusive no requiere de la aprobación por parte del empleador, es un acto de libre voluntad. "La decisión del trabajador de poner fin a la relación laboral constituye causa suficiente para la extinción valida de esta"17.

Un aspecto importante a destacar es que se establece en la regulación, una mayor flexibilidad al trabajador para extinguir el contrato de trabajo. Esta situación tiene como base el respeto a la libertad de trabajo, en cuanto, no puede obligar al trabajador a laborar de manera en contra de su voluntad ${ }^{18}$.

Si se estableciera muchas trabas para poder extinguir el contrato de trabajo o se impidiera terminarlo, estaríamos ante supuestos de violación de aquel derecho constitucional ${ }^{19}$. De lo anterior se tiene que, no es necesario la expresión de causa para la renuncia, por tanto, basta la sola comunicación cierta que se haga al empleador, para que la renuncia surta efectos, sin embargo, esta decisión debe ser comunicada con anticipación al empleador ${ }^{20}$, a fin de que este pueda adoptar las medidas pertinentes a fin de reemplazar al trabajador renunciante. En el caso del congresista renunciante, debe suceder lo mismo, a fin de que su accesitario pueda asumir el cargo. Este acto de renunciar, en el caso de los congresistas, inclusive no requeriría ni siquiera que sea presentado por escrito, pues podría hacerse de forma verbal, por ejemplo, en una sesión del congreso, no olvidemos que la naturaleza del congreso, es de ser un parlamento, donde la expresión de la palabra tiene un papel importantísimo.

La falta de necesidad de una causa que justifique la terminación de la relación laboral de trabajo es una expresión del principio protector del Derecho del Trabajo y, como se ha señalado, de la libertad de trabajo ${ }^{21}$.

Respecto a su aceptación, concordamos con lo expresado por Cortez Carcelen "Se ha discutido si la sola voluntad del trabajador, es insuficiente en la relación laboral con entidades públicas, en la que la renuncia tiene que ser aceptada. Desde nuestro punto de vista, no es ni debería ser necesaria una declaración de la administración, porque de lo contrario no estamos ante una renuncia, y en todo caso, si se aceptara esta declaración de la entidad estaríamos ante un supuesto en el cual la libertad de trabajo estaría supeditada a la subjetividad de un funcionario"22.

\footnotetext{
16 DE BUEN LOZANO, Nestor y MORGADO VALENZUELA, Emilio. Instituciones de Derecho de Trabajo y de la Seguridad Social. Mexico 1997. Pag. 512.

17 BLANCAS BuStamante, Carlos. El despido en el Derecho Laboral Peruano. Tercera Edición. Jurista Editores. Pag. 42.

18 CORTEZ CARCELEN, Juan Carlos, Temas sobre la regulación de la renuncia en el Perú. En Trabajo y Seguridad Social. Estudios Jurídicos en Homenaje a Luis Aparicio Valdez. Editorial Grijley. Lima 2008. Pag. 304.

19 Idem.

20 Según el artículo 18 de la Ley de Productividad y Competitividad Laboral, el trabajador debe dar aviso a su empleador su decisión de renunciar con 30 días de anticipación.

21 CORTEZ CARCELEN, Juan Carlos, Temas sobre la regulación de la renuncia en el Perú. En Trabajo y Seguridad Social. Estudios Jurídicos en Homenaje a Luis Aparicio Valdez. Editorial Grijley. Lima 2008. Pag. 305.

22 Idem.
} 


\subsection{2.- La Renuncia en los otros Poderes del Estado}

De conformidad con el artículo 43 de la Constitución Política del Perú La República del Perú es democrática, social, independiente y soberana. El Estado es uno e indivisible. Su gobierno es unitario, representativo y descentralizado, y se organiza según el principio de la separación de poderes.

Lo evidente es que la separación de poderes significa muy claramente que el poder del Estado, debe ser ejercitado por diferentes órganos cada uno de los cuales tiene su propio grupo de atribuciones que realizar al tiempo que controla a los demás, en la manera como ejecutan las suyas ${ }^{23}$.

La teoría de la división de poderes, pasará a ser una teoría positiva, no de limitación de un poder ajeno, sino de configuración limitadora de un poder propio de la sociedad. De esta manera comprensiva, adaptándose a ellas la configuración de los órganos constitucionales ${ }^{24}$.

Bajo este contexto aceptado casi universalmente respecto de la separación de poderes en el estado, se tiene un poder ejecutivo, un poder legislativo y un poder judicial, pues bien veamos la renuncia en los otros poderes del Estado.

En cuanto al Poder Ejecutivo, la Constitución Política del Perú, respecto del mandatario de la nación, establece que el Presidente de la República, es el Jefe del Estado y personifica a la Nación, se elige por sufragio directo y su mandato presidencial es de cinco años, no hay reelección inmediata. Respecto de la Vacancia de la Presidencia de la República, el artículo 113 del texto constitucional prescribe: La Presidencia de la República vaca por:...3. Aceptación de su renuncia por el Congreso.

En el caso del Poder Judicial, el Presidente de la Corte Suprema, lo es también del Poder Judicial. El presidente de este poder del estado, es un juez, un juez supremo y de conformidad con el artículo 107, de la Ley 29277, Ley de la Carrera Judicial, el cargo de Juez termina por:.. 3. renuncia, desde que es aceptada.

Conforme es de verse, en los otros dos poderes del estado llámese, ejecutivo y judicial la renuncia de sus titulares, es una causal de conclusión del mandato, no permitir la renuncia en el caso de congresistas definitivamente es discriminatorio.

\subsection{3.- La Renuncia en los Órganos Constitucionalmente Autónomos}

Junto a los tres poderes del Estado, encontramos a los órganos constitucionalmente autónomos, que son aquellas entidades del Estado que se caracterizan por tener competencias distintas a las que tienen los tres poderes clásicos del Estado, es decir, aquellos órganos distintos al poder Ejecutivo, Legislativo y Judicial.

Los órganos constitucionalmente autónomos “...hacen referencia a la pluralidad de unidades personales que tienen a su cargo competencias destinadas a perfeccionar la actuación del Estado" 25 . En el Perú el texto

\footnotetext{
23 RUBIO CORREA, Marcial. Estudio de la Constitución Política de 1993. PUCP. Tomo III. Lima 1999. Pag. 48.

24 PEREZ BORJA, Jerónimo. La Separación de Poderes. En Curso de Derecho Constitucional. Marcial Pons. Madrid. 1994. Pag. 422.

25 GARCIA TOMA, Víctor. Teoría del Estado y Derecho Constitucional. Editorial Adrus. Lima 2010. Pag. 222.
} 
fundamental ha determinado la calidad de órganos constitucionalmente autónomos, a favor de los entes siguientes: el Tribunal Constitucional, el Jurado Nacional de Elecciones, la Oficina Nacional de Procesos Electorales, el Registro Nacional de Identificación y Estado Civil, la Defensoría del Pueblo, la Contraloría General de la República, el Consejo Nacional de la Magistratura, el Banco Central de Reserva y la Superintendencia Nacional de Banca y Seguros ${ }^{26}$. Veamos, como funciona la renuncia en cada una de estas entidades:

En el Tribunal Constitucional. La Ley 28031, Ley Orgánica del Tribunal Constitucional en el artículo 16, prescribe que el cargo de Magistrado del Tribunal vaca por cualquiera de las siguientes causas: 2. Por renuncia.

En el Jurado Nacional de Elecciones. La Ley 26486, Ley Orgánica del Jurado Nacional de Elecciones, en su artículo 18, establece que son causales de vacancia de miembro del Pleno del Jurado Nacional de Elecciones las siguientes: a. Renuncia, sin perjuicio de la limitación contenida en el Artículo 16 de la presente ley. En la Oficina Nacional de Procesos Electorales. La Ley 26487, Ley Orgánica de la Oficina Nacional de Procesos Electorales, en su artículo 14, establece que son causales de vacancia del cargo de Jefe de la Oficina Nacional de Procesos Electorales las siguientes: a) Renuncia, sin perjuicio de la limitación contenida en el Artículo 10 de la presente ley.

En el Registro Nacional de Identificación y Estado Civil. La Ley 26497, Ley Orgánica de la RENIEC, en su artículo 13, establece que son causales de vacancia del cargo de Jefe del Registro Nacional de Identificación y Estado Civil: a) Renuncia.

En la Defensoría del Pueblo. La Ley 26520, Ley Orgánica de la Defensoría del Pueblo en su artículo 4, prescribe: El Defensor del Pueblo, cesará por alguna de las siguientes causas: 1. Por renuncia.

En la Contraloría General de la República, la Ley 27785, Ley Orgánica de la Contraloría General de la República en su artículo 30, establece que el cargo de Contralor General de la República vaca por: ...c) Renuncia.

En el Consejo Nacional de la Magistratura, la Ley 26397, Ley Orgánica del Consejo Nacional de la Magistratura, prescribe en su Artículo 11.- El cargo de Consejero vaca por las siguientes causas: inciso 2. Por renuncia.

En el Banco Central de Reserva del Perú. El Decreto Ley 26123 Ley Orgánica del Banco Central de Reserva del Perú en su artículo 17, prescribe que el cargo de Director vaca por:...f) Renuncia aceptada.

En la Superintendencia Nacional de Banca y Seguros, la Ley 26702 Ley General del Sistema Financieros y del Sistema de Seguros y Orgánica de la Superintendencia de Banca y Seguros, en su artículo 363, regula que si por cualquier causa no completare el período para el que fue nombrado, su reemplazante será designado dentro de los sesenta (60) días posteriores a su cese, quien desempeñará el cargo por un período constitucional que lo nombró, con arreglo a lo establecido en el párrafo precedente. Respecto a este último caso tenemos que en el año 20154, durante el gobierno de Ollanta Humala, el Superintendente de Banca, Seguros y AFPs, Daniel Schydlowsky renuncio a su cargo, luego de producirse un escándalo por haber prepublicado las nuevas tablas de mortalidad y el incremento de la esperanza de vida de los peruanos (mujeres a 90 y varones a 87 años). 


\subsection{4.- La Renuncia en los Regímenes Laborales del Estado.}

Según el SERVIR, en la actualidad en el Estado peruano coexisten 15 regímenes laborales, sujetos a esta institución, sin embargo, atendiendo a su importancia cuántica, nos referiremos a los 3 principales: los trabajadores sujetos a la ley de la carrera pública, los trabajadores estatales sujetos al régimen de la actividad privada y los trabajadores estatales sujetos al régimen de la contratación administrativa de servicios.

De conformidad con el D. Leg. 276, Ley de la Carrera Pública, la carrera administrativa es el conjunto de principios, normas y procesos que regulan el ingreso, los derechos y los deberes que corresponden a los servidores públicos que, con carácter estable prestan servicios de naturaleza permanente en la Administración Pública, el artículo 34 de esta norma, prescribe que la Carrera Administrativa termina por:... b) Renuncia.

Respecto al régimen laboral de la actividad privada, en el cual se encuentran un gran número de trabajadores públicos, el D.S. 003-97-TR, Ley de Productividad y Competitividad Laboral, en su artículo 16, establece que son causas de extinción del contrato de trabajo:...b) La renuncia.

Por otro lado, el D. Leg. 1057, que regula el régimen especial de contratación administrativa de servicios, y que tiene por objeto garantizar los principios de méritos y capacidad, igualdad de oportunidades y profesionalismo de la administración pública, en su artículo 10, prescribe: El Contrato Administrativo de Servicios se extingue por: c) Renuncia.

\section{6.- La Relación Laboral del Congresista}

Previamente es necesario tener en cuenta el concepto función pública; por función pública debe entenderse toda actividad temporal o permanente, remunerada $u$ honoraria, realizada por una persona natural en nombre del Estado o al servicio del Estado, o de sus entidades, en cualquiera de sus niveles jerárquicos.

La Convención de las Naciones Unidas contra la Corrupción ${ }^{27}$, considera "funcionario público" a toda persona que ocupe un cargo legislativo, ejecutivo, administrativo o judicial de un Estado Parte, ya sea designado o elegido, permanente o temporal, remunerado u honorario, sea cual sea la antigüedad de esa persona en el cargo, o toda persona que desempeña una función pública, incluso para un organismo público o una empresa pública, o que preste un servicio público.

El Tribunal Constitucional ${ }^{28}$ ha emitido una sentencia en el año 2003, estableciendo que los congresistas tienen la condición de "funcionarios públicos", y el propio Reglamento del Congreso, así lo reconoce al establecer en su artículo 21 que los congresistas son funcionarios públicos al servicio de la Nación. No están comprendidos en la carrera administrativa, salvo en las disposiciones establecidas en el Decreto Legislativo 276, en lo que les fuera aplicable. No pueden ejercer los derechos de sindicación y huelga.

\footnotetext{
27 Convención de las Naciones Unidas contra la Corrupción, de fecha 31de octubre del 2003 aprobada por el Congreso de la República mediante Resolución Legislativa $\mathrm{N}^{\circ} 28357$ del 06 de octubre de 2004.

28 Expediente $\mathrm{N}^{\circ}$ 0006-2003-AI/TC - Acción de Inconstitucional interpuesta por 65 congresistas contra el inciso j) del artículo $89^{\circ}$ del Reglamento del Congreso de la República, de fecha 1 de diciembre del 2003.
} 
Ahora se hace necesario tener presente cual es la naturaleza jurídica de la relación laboral que tienen los congresistas, pues bien, veamos los elementos esenciales de la relación laboral, los cuales son los siguientes: La prestación personal, la subordinación y la remuneración.

Entiéndase por prestación personal “...la actividad cuya utilización es objeto del contrato de trabajo, es la especifica de un trabajador determinado, de aquí deriva que el trabajador es siempre una persona humana a diferencia del empleador, en que puede desempeñarse como tal una persona natural o jurídica"29.

En tanto que "la subordinación es un vinculo jurídico entre el deudor y el acreedor de trabajo, en virtud del cual el primero le ofrece su actividad al segundo y le confiere el poder de conducirla" ${ }^{30}$.

Mientras que la remuneración es todo lo que en especie o dinero recibe el trabajador como contraprestación por la labor realizada.

Cumpliendo con los tres elementos antes mencionados podemos concluir que el congresista tiene un contrato de trabajo, por tanto mantiene, una relación laboral con el Estado.

Conforme tenemos dicho anteriormente de conformidad con el artículo 21 del Reglamento del Congreso, los congresistas son funcionarios públicos, es decir, se le aplica en lo que fuera pertinente el D. Leg. 276, Ley de la Carrera Pública, sin embargo, cuando se refieren a temas remunerativos se les aplica las normas del régimen laboral de la actividad privada, como es el caso de las gratificaciones, la compensación por tiempo de servicios y otros.

De lo anterior se puede concluir que el congresista mantiene una relación laboral con el estado de naturaleza sui generis.

\section{7.- Limites a la Renuncia al Cargo de Congresista}

No faltara alguien quien diga, que pasa si dejamos la puerta abierta y un número considerable de congresistas renuncian, si renuncian varias bancadas y hasta un hipotético caso extremo de la renuncia de todos los congresistas, pues bien, tendrían que ponerse algunos parámetros, como por ejemplo:

Un plazo para poder hace efectiva la renuncia, por ejemplo con 60 días de anticipación, eso con la finalidad de que el accesitario, pueda recepcionar su credencial, prestar el juramento de Ley y asumir funciones.

Por otro lado se podría establecer que la renuncia no podrá presentarse el primer año de ejercicio de la función, ni el último año, esto con la finalidad de evitar renuncias prematuras, sin que conozcan por si mismos la labor parlamentaria, y por otro lado a fin de evitar que el accesitario, asuma la función de congresista por un lapso muy corto.

\footnotetext{
29 NEVES MUJICA, Javier. Introducción al Derecho Laboral. Pontificia Universidad Católica del Perú. Fondo Editorial Lima 2003. Pag. 29.

30 Idem.
} 
Finalmente, la renuncia de los congresistas se aceptará en la misma legislatura, hasta por un porcentaje no superior a un tercio del número legal de congresistas, a fin de evitar una renuncia masiva de congresistas que podría perjudicar el desarrollo normal del parlamento.

\section{8.- Conclusiones}

$>$ El congresista mantiene una relación laboral con el Estado de naturaleza sui generis, en razón que, conforme tenemos dicho, son funcionarios públicos, por tanto, se les aplica las normas del D. Leg. 276, Ley de la Carrera Pública, sin embargo, respecto a los temas remunerativos se les aplica las normas del régimen laboral de la actividad privada D. Leg. 728 y además las normas propias de la función parlamentaria.

$>\quad$ La renuncia, como acto voluntario y consciente del trabajador, es un derecho que forma parte del derecho laboral y por su naturaleza, no forma parte de las prerrogativas parlamentarias.

$>$ El carácter irrenunciable del cargo de congresista, que en la actualidad prescribe el texto constitucional, lesiona otros derechos constitucionales, como son el derecho al libre desarrollo, a la igualdad ante la ley, a trabajar libremente con sujeción a la ley, a trabajar con su libre consentimiento, el acceso y permanencia en los cargos representativos y la garantía de la libertad de trabajo.

$>\quad$ La renuncia, es un derecho que puede ser ejercido dentro del ámbito del derecho laboral público y también dentro del derecho laboral privado, en el caso específico de los trabajadores estatales, todos los trabajadores tienen este derecho, independientemente de su régimen laboral, inclusive el Presidente de la República y el Presidente del Poder Judicial, gozan de este derecho.

> A fin de garantizar la libertad de trabajo, se debe modificar el artículo 95 de la Constitución de 1993, permitiendo la renuncia al cargo de congresista. 


\section{*Bibliografía}

- $\quad$ BLANCAS BUSTAMANTE, Carlos. El despido en el Derecho Laboral Peruano. Tercera Edición. Jurista Editores. Lima 2013.

- Convención de las Naciones Unidas contra la Corrupción, de fecha 31de octubre del 2003 aprobada por el Congreso de la República mediante Resolución Legislativa № 28357 del 06 de octubre de 2004.

- $\quad$ CORTEZ CARCELEN, Juan Carlos, Temas sobre la regulación de la renuncia en el Perú. En Trabajo y Seguridad Social. Estudios Jurídicos en Homenaje a Luis Aparicio Valdez. Editorial Grijley. Lima 2008.

- DE BUEN LOZANO, Nestor y MORGADO VALENZUELA, Emilio. Instituciones de Derecho de Trabajo y de la Seguridad Social. México 1997.

- $\quad$ DOMINGUEZ HARO. Heder. La llamada Constitución Histórica. Diario El Peruano. 12 de agosto del 2011.

- $\quad$ Expediente N0006-2003-AI/TC - Acción de Inconstitucional.

- $\quad$ GARCIA TOMA, Víctor. Teoría del Estado y Derecho Constitucional. Editorial Adrus. Lima 2010.

- $\quad$ GREGORIO PECES - BARBA MARTINEZ. Curso de Derechos Fundamentales. Madrid 1996.

- $\quad$ La Constitución Comentada. Gaceta Jurídica. Lima 2005.

- $\quad$ LEVAGGI. Virgilio. Democracia y Trabajo Decente en América Latina. OIT. Lima 2006.

- $\quad$ NEVES MUJICA, Javier. Introducción al Derecho Laboral. Pontificia Universidad Católica del Perú. Fondo Editorial Lima 2003.

- PEREZ BORJA, Jerónimo. La Separación de Poderes. En Curso de Derecho Constitucional. Marcial Pons. Madrid. 1994.

- $\quad$ PÉREZ ROYO, Javier. Curso de Derecho Constitucional. Marcial Pons Ediciones Jurídicas. Madrid 2005.

- $\quad$ Revista Derecho y Sociedad N ${ }^{\circ} 31$. Asociación Civil Derecho \& Sociedad. Entrevista realizada por Sandra Cecilia Chávez Torres y Ulises Medrana Recuay, al Doctor Francisco Eguiguren Praeli. El Parlamento Peruano y las Funciones del Parlamentario: lo que se Puede Mejorar. Año 2008.

- $\quad$ RUBIO CORREA, Marcial. Estudio de la Constitución Política de 1993. PUCP. Tomo I Lima 1999. 
- $\quad$ VALLE RIESTRA, Javier. La viabilidad de la renuncia al cargo parlamentario. En Revista Institucional N 9 AMAG. Lima 2010. 